Case Report

\title{
Congenital lipoma of the lip: a case report
}

\author{
Hécio H. A. Morais ${ }^{1,2)}$, André Vajgel ${ }^{3)}$, Nelson S. Rocha ${ }^{1)}$, Ricardo W. F. Carvalho ${ }^{4)}$, \\ Antonio F. Caubi ${ }^{4)}$ and Ricardo J. H. Vasconcellos ${ }^{4)}$ \\ ${ }^{1)}$ Doctorate Program in Oral and Maxillofacial Surgery, Department of Oral and Maxillofacial Surgery, \\ Pernambuco School of Dentistry, University of Pernambuco, Recife, Brazil \\ ${ }^{2)}$ Department of Oral and Maxillofacial Surgery, School of Dentistry, Rio Grande do Norte State University, \\ Caicó, Brazil \\ ${ }^{3)}$ Program of $\mathrm{MsC}$ in Oral and Maxillofacial Surgery, Department of Oral and Maxillofacial Surgery, \\ Pernambuco School of Dentistry, University of Pernambuco, Recife, Brazil \\ ${ }^{4)}$ Department of Oral and Maxillofacial Surgery, Oswaldo Cruz Hospital and Pernambuco School of Dentistry, \\ University of Pernambuco, Recife, Brazil
}

(Received 8 January and accepted 6 June 2009)

\begin{abstract}
We describe a rare case of large congenital lipoma in the upper lip of a six-month-old infant. Surgical excision of the tumor was successful, with satisfactory esthetic and functional results. (J Oral Sci $51,489-491,2009$ )
\end{abstract}

Keywords: mouth neoplasms; adipose tissue; lipoma; congenital.

\section{Introduction}

Lipoma is the most common benign mesenchymal tumor and can develop in any site where adipose tissue is present. It mainly occurs in subcutaneous tissue, but can also present in deeper regions. Peak occurrence is mainly in the fifth or sixth decades of life, and the tumor is uncommon in childhood (1). Although 15 to $20 \%$ of these tumors occur in the head and neck region, only 1 to $4 \%$ affect the oral cavity, representing 0.1 to $5 \%$ of all benign tumors of the mouth (2).

This report describes a rare case of large congenital lipoma in the upper lip of a six-month-old infant.

Correspondence to Dr. Hécio Henrique Araújo Morais, Faculdade de Odontologia de Pernambuco - FOP/UPE, Av. General Newton Cavalcanti, 1650, Tabatinga, 54753-220, Camaragibe Pernambuco, Brazil

Tel: $+55-81-88868677$

Fax: +55-81-34582867

E-mail: wathson@ig.com.br

\section{Case Report}

A six-month-old girl was referred to the Department of Oral and Maxillofacial Surgery. Her mother had noticed increased swelling of the child's upper lip. A mass of soft tissue had been observed in the upper lip at birth, but no treatment was performed at that stage. The mass appeared to be gradually enlarging. The mother also reported difficulties in breastfeeding the child, as the tumor rendered lip seal to the breast impossible. Maxillofacial examination revealed an increased volume of the upper lip; the mass had a soft consistency, well-defined edges, no pulsation, and was symptomatic upon palpation (Fig. 1A). The lesion had a sessile base and the overlying mucosa appeared normal. Due to the large dimensions of the tumor, the child exhibited lip incompetence, with dryness of the oral mucosa and a mouth-breathing pattern. No radiographic abnormalities were observed. The proposed treatment was excision biopsy under general anesthesia. Aspiration was first performed, which was negative (Fig. 1B). A surface incision was made in the labial mucosa, followed by submucosal dissection. This clearly showed a yellowish mass, which could be well delimited and excised after exposure (Fig. 1C and 2A). The excised tumor (Fig. 2B) was sent for histopathological analysis, the result of which was lipoma (Fig. 2C). The child has been followed up for two years, exhibiting satisfactory esthetics and function, with no signs of recurrence (Fig. 2D). 


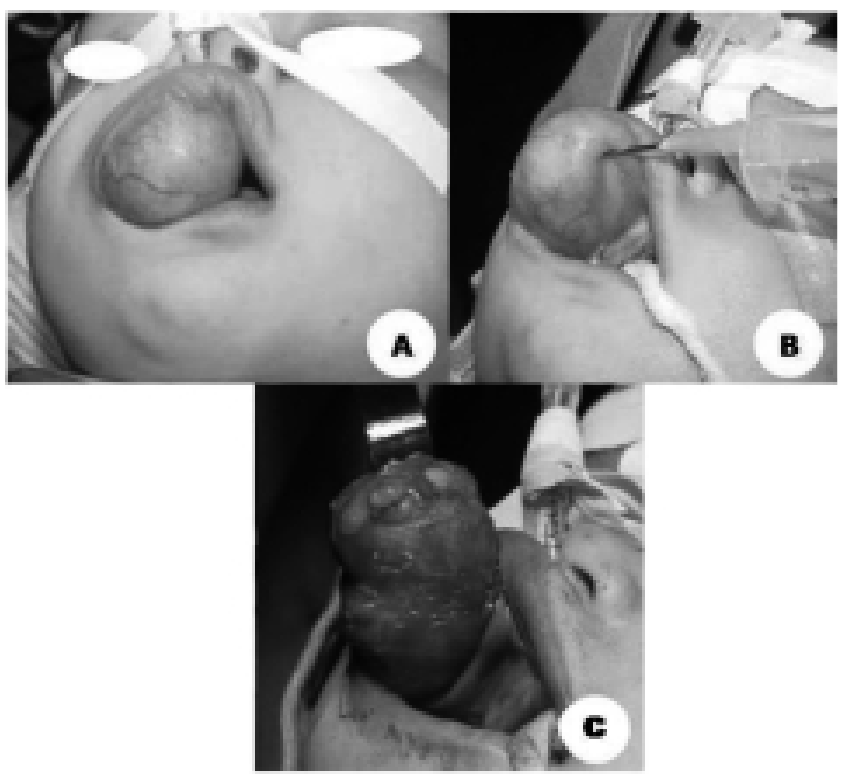

Fig. 1 (A) Frontal view of the lesion; (B) Negative aspiration; (C) Exteriorization of the tumor.

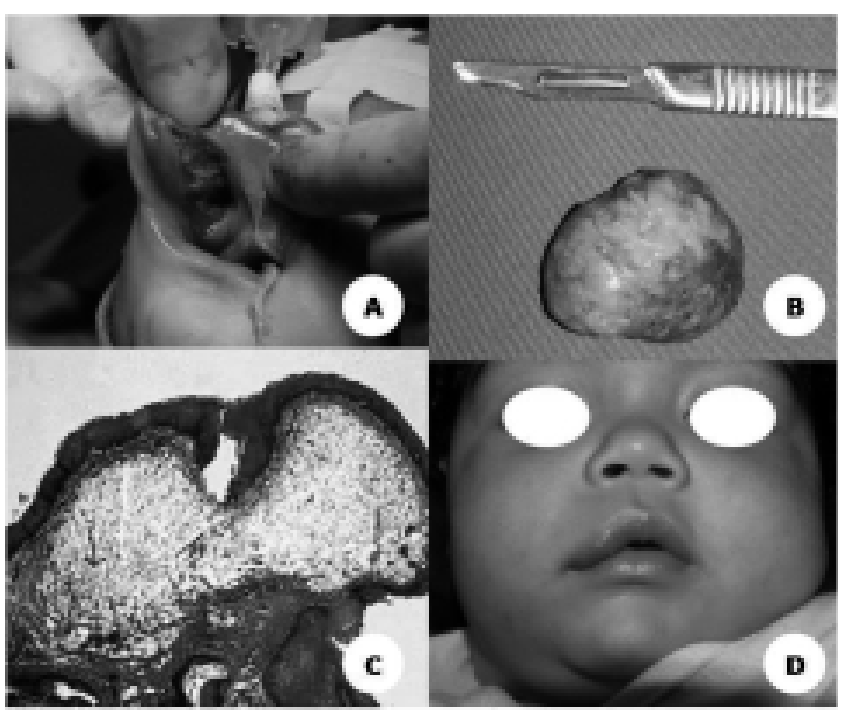

Fig. 2 (A) Surgical site; (B) Excised tumor; (C) Histological appearance; (D) 2 years after operation.

\section{Discussion}

Congenital lipoma in the oral cavity is a rare entity and its appearance in the lip is even rarer. Few cases of congenital lipoma are reported in the literature and none were found regarding lipoma affecting the lip. De Carvalho et al. (3), Dimitrakopoulos et al. (4), and Mahabir et al. (5) reported congenital lipoma in the vestibular fornix of a seven-month-old boy, the tongue of a 20-day-old girl and the soft palate of an eight-month-old boy, respectively.
The histogenesis of this lesion remains unclear. A study of the embryogenesis of fat tissue reveals that it appears in the embryo, and the formation of new lobules ceases in late fetal life or the early postnatal period (6). Lipoma is thought to result from a continuation of the proliferation of these fat tissue lobules.

The distinction between benign neoplasm, malformation, and hyperplasia may not be clinically clear. Lipoma in adults is commonly considered a neoplasm, whereas in children it is classified as either a neoplasm or malformation (7). Solitary lipomas, such as those found in the present case, are considered true neoplasms rather than developmental malformations.

Clinically, lipomas are generally mobile, painless, submucosal nodules with a yellowish color; these characteristics were all noted in the congenital variant described here. Due to these clinical characteristics, other lesions should be considered in the differential diagnosis of oral lipoma, such as dermoid and epidermoid cysts and congenital lip entities, including common vascular lesions (hemangioma and lymphangioma), benign mesenchymoma, and mucous cysts (8). However, these lesions may occur at other sites of the oral mucosa. Mesenchymal tumors should also be included in the differential diagnosis (9).

It is unusual for children to have classic lipomas; lipoblastoma and lipoblastomatosis are more often diagnosed in pediatric patients (1). Given its congenital nature, lipoblastoma, although rare, should also be included in the histological differential diagnosis. Thus, a discerning clinical diagnosis and histological analysis is important for diagnostic confirmation.

Congenital lipomas have been reported but are rare $(7,9)$, and in some, familial predisposition (7) has been suggested; however this was not indicated in the present case. Congenital lipoma is commonly described in association with craniofacial anomalies. For example, congenital lipoma was described in an uncommon case of oral-facial-digital syndrome, differing from the standard pattern by exhibiting congenital lipoma rather than the hamartoma of the tongue normally described. The authors described this as a variant of type II oral-facial-digital syndrome (7).

Congenital lipoma is an extremely rare benign lipomatous tumor. The case described here exhibited the classic features of this condition. Surgical excision of the tumor was successful, with the child exhibiting satisfactory esthetics and function, with no signs of recurrence.

\section{References}

1. Furlong MA, Fanburg-Smith JC, Childers EL (2004) 
Lipoma of the oral and maxillofacial region: site and subclassification of 125 cases. Oral Surg Oral Med Oral Pathol Oral Radiol Endod 98, 441-450.

2. Fregnani ER, Pires FR, Falzoni R, Lopes MA, Vargas PA (2003) Lipomas of the oral cavity: clinical findings, histological classification and proliferative activity of 46 cases. Int J Oral Maxillofac Surg 32, 49-53.

3. Dimitrakopoulos I, Zouloumis L, Trigonidis G (1990) Congenital lipoma of the tongue. Report of a case. Int J Oral Maxillofac Surg 19, 208.

4. Perri de Carvalho AC, Martinelli C, Sanches MG (1987) Congenital lipoma in the oral cavity. A case report. Quintessence Int 18, 799-802.

5. Mahabir RC, Mohammad JA, Courtemanche DJ (2000) Lipoma of the cleft soft palate: a case report of a rare congenital anomaly. Cleft Palate Craniofac
J 37, 503-505.

6. Vellios F, Baez J, Shumacker HB (1958) Lipoblastomatosis: a tumor of fetal fat different from hibernoma; report of a case, with observations on the embryogenesis of human adipose tissue. Am J Pathol 34, 1149-1159.

7. Ghossaini SN, Hadi U, Tawil A (2002) Oral-facialdigital syndrome type II variant associated with congenital tongue lipoma. Oral Surg Oral Med Oral Pathol Oral Radiol Endod 94, 324-327.

8. Bandéca MC, de Pádua JM, Nadalin MR, Ozório JEV, Silva-Sousa YTC, da Cruz Perez DE (2007) Oral soft tissue lipomas: a case series. J Can Dent Assoc 73, 431-434.

9. Yonezawa H, Harada K, Enomoto S (2000) Congenital lipomatoid mass of the tongue. Int $\mathrm{J}$ Oral Maxillofac Surg 29, 138-139. 